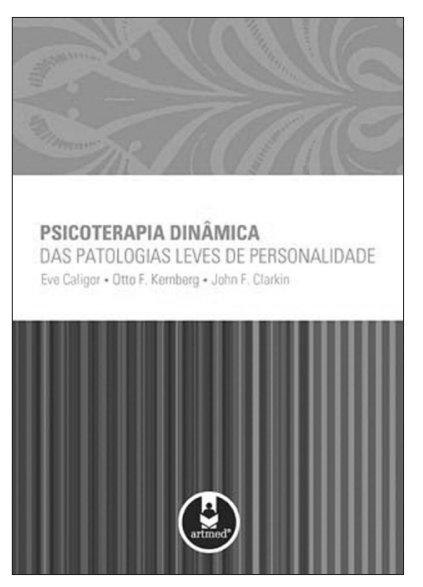

\title{
Psicoterapia dinâmica das patologias leves de personalidade
}

\author{
Eve Caligor, Otto F. Kernberg e John F. Clarkin \\ Porto Alegre, Artmed, 2008 \\ Marianne de Aguiar Possa*
}

Publicado originalmente em inglês (Handbook of dynamic psychotherapy for higher level personality pathology), o livro Psicoterapia dinâmica das patologias leves de personalidade foi lançado pela editora Artmed em versão para o português em 2008. Direcionado tanto a estudantes de psicoterapia quanto a clínicos mais experientes, a obra descreve uma forma específica de tratamento psicodinâmico das patologias leves de personalidade (PDPLP), baseado na teoria psicodinâmica contemporânea das relações objetais. As bases dessa forma psicoterapia consistem na exploração e modificação dos padrões disfuncionais de relacionamentos internalizados e na introdução de um maior grau de flexibilidade nas operações defensivas do paciente, aliviando sintomas e traços de personalidade mal-adaptativos.

O modelo de tratamento em que se baseia o livro é produto da psicoterapia focada na transferência (PFT), um tipo de psicoterapia psicodinâmica desenvolvida e testada no Instituto de Transtornos de Personalidade da Sanford Weill Cornell Medical College para tratamento dos transtornos de personalidade graves, como o borderline. A PFT é singular comparada a outras formas de psicoterapia psicodinâmica de longa duração por ter sido desenvolvida especificamente para tratar transtornos graves de personalidade e suas particularidades, por ter suas técnicas descritas passo a passo em um manual de tratamento focado nas necessidades comuns aos portadores dessa patologia, além de ter sido validada empiricamente.
O objetivo do livro é preencher a lacuna estabelecida no conhecimento de um tratamento específico, comparável à PFT, para as patologias leves de personalidade, que são os transtornos de personalidade bastante frequentes nos consultórios, em que há o predomínio da utilização de mecanismos de defesa mais evoluídos, configurando o nível neurótico de organização de personalidade, com sintomas vagos de transtornos de humor e ansiedade, além de padrões repetitivos de relacionamentos disfuncionais. Os autores apresentam uma abordagem sistemática, clara e específica de psicoterapia, útil para os clínicos mais experientes e que também pode ser usada para treinamento clínico e como manual de tratamento em um contexto de pesquisa.

Ao mesmo tempo em que os autores sistematizam e definem os princípios do tratamento de forma precisa dentro de um referencial psicodinâmico, salientam que "um tratamento desse tipo não pode ser reduzido a uma série de passos a serem seguidos de maneira padronizada por qualquer terapeuta que esteja tratando qualquer paciente". Esse alerta indica a importância da escuta reflexiva, do uso da contratransferência, da supervisão e do tratamento pessoal para o desenvolvimento de uma boa psicoterapia. O uso de ilustrações clínicas ao longo de todo o texto facilita o entendimento da teoria e da técnica dentro do contexto da prática clínica.

A obra é subdividida em três partes. Inicialmente, é estabelecida a compreensão teórica das patologias leves

\footnotetext{
* Médica psiquiatra, Hospital de Clínicas de Porto Alegre (HCPA), Porto Alegre, RS, Brasil. Especialista em Psicoterapia de Orientação Analítica, Universidade Federal do Rio Grande do Sul (UFRGS), Porto Alegre, RS, Brasil.

Recebido em 26/04/2011. Aceito em 03/07/2011. Não foram declarados conflitos de interesse associados à publicação desta resenha.

Como citar: Possa MA. Psicoterapia dinâmica das patologias leves de personalidade [resenha]. Trends Psychiatry Psychother. 2012;34(1):44-5.
} 
de personalidade, com definições dos termos e aplicação da teoria das relações objetais à compreensão dos transtornos de personalidade, conforme desenvolvida por Otto Kernberg. O grau de disfunção irá depender do grau de rigidez de personalidade, o nível de organização das defesas, o grau de patologia da identidade e de comprometimento do teste de realidade.

Após, enfatiza-se o tratamento psicoterápico através de estratégias, delimitação do setting terapêutico, técnicas e táticas. As estratégias de tratamento incluem: definir as relações objetais dominantes, explorar e interpretar os conflitos e defesas, limitar o foco aos objetivos do tratamento, elaborar os conflitos identificados. O setting e as técnicas utilizadas seguem os princípios da psicoterapia psicodinâmica de longo prazo, como frequência de duas vezes por semana, sessões de 45 a 50 minutos com horários estabelecidos previamente, uso da neutralidade, transferência, contratransferência, continência, interpretação, análise de resistências, etc. Já as técnicas e táticas do tratamento são os componentes que guiam o terapeuta em cada sessão na decisão de como implementar as técnicas. São elas: identificação de um tema prioritário, baseado no afeto dominante; definição do conflito; análise sistemática do conflito dominante; e análise da relação entre o conflito dominante e os objetivos do tratamento. Por último, os autores descrevem a avaliação do pacientes, as fases do tratamento e a combinação da PDPLP com outros tratamentos, incluindo o medicamentoso.

A grande contribuição deste livro e sua inovação é a criação de um manual que sistematiza e padroniza a PDPLP, útil tanto para a prática clínica como para assegurar o uso de uma técnica competente para a realização de pesquisas, também proporcionando treinamento adequado àqueles que o utilizam. Ao mesmo tempo, garante uma implementação flexível mas consistente da teoria e da técnica, o que é o grande desafio na prática clínica.

\section{Correspondência:}

Rua Felipe Neri, 366/204, Auxiliadora

90440-150 - Porto Alegre, RS - Brasil

Tel.: +55 (51) 2112.3343

E-mail: mariannepossa02@yahoo.com.br 